\title{
ATTITUDES OF PLWHA AND OTHER SELECTED COMMUNITIES IN TSABONG TOWARDS OPERATIONALISING BIOMEDICAL AND TRADITIONAL THERAPIES IN TANDEM TO FACE THE AIDS EPIDEMIC
}

\section{Simon Kang'ethe}

\section{STUDY AIMS AND OBJECTIVES}

Though the broad research study from which this article is derived was designed to assess the levels of stigma and discrimination in Tsabong District, the aim and objective of this article is to assess the attitudes of Tsabong people living with HIV/AIDS, along with those of a few Tsabong care service providers and a few members of civil society to the challenges and gaps inherent in the work of biomedical and traditional healers in HIV/AIDS service delivery. It also investigates the possibility of collaboration between the two systems.

\section{OPERATIONAL DEFINITION}

Traditional healers refers to either herbalists, spiritualists, or to those (the great majority of healers) involved in both practices.

\section{PROBLEM STATEMENT}

The researcher was prompted to investigate the justification for seeking collaboration between both biomedical practitioners and traditional healers in the light of the fact that traditional healers hold an esteemed and powerful position in many African societies. In these societies they perform the roles of physician, counsellor, psychiatrist and priest, and people visit them to deal with problems ranging from social dilemmas to major medical illnesses (King \& Homsy, 1997; UNAIDS, 2000). This approach has also been supported by the World Health Organisation and other official groups, who acknowledge the potential effectiveness of traditional healers as primary caregivers and the potential efficacy of their treatments in the fight against HIV and AIDS, sexually transmitted diseases and other infectious diseases. The researcher, therefore, felt justified in seeking the views and attitudes of PLWHA and selected communities from Tsabong to investigate the grounds for collaboration and the integration of the healers' therapies into mainstream health services. The objective of the investigation is also strengthened by the fact that World Health Organization supports the integration of Western medicine and traditional healing, especially encouraging referrals between the two.

Worrying reports of myths and wrong or misleading messages believed to come from traditional healers, who are key players in medical diagnosis and prescription for people living with HIV/AIDS especially in the most rural areas in Botswana, led to this research - with the assistance of two other members of the Botswana Network of People Living with HIV/AIDS (BONEPWA) on communities living with HIV/AIDS. Other important selected key persons, such as chiefs and church pastors, were also consulted on the possible challenges emanating from using the services of both biomedical practitioners and traditional healers in tandem. Such myths and messages could be corrected if the results were well documented in a paper like this, which can become a platform of advocacy to persuade the government and other donors to move fast to address the documented challenge.

Increased cases of antiretroviral drugs (ARV) defaulters have been a worrying phenomenon nationally and the BONEPWA team felt that challenges of that nature could be attributed to 
many factors, such as confusion resulting from the use of biomedical and traditional healers in tandem. The researcher and the BONEPWA team therefore felt that informed research could shed light on this situation on the basis of evidence. The author also felt that defaulting could be interpreted as a national failure of the ARV programme in which the government has invested heavily. If these challenges were not addressed timeously, the country's advance towards universal access and the Millennium Development Goals could be affected negatively (UNAIDS, 2002). The author also felt that it was of the utmost importance to ascertain what happened when clients moved from traditional healers to biomedical practitioners and vice versa. It was hoped that this research would reveal the attitudes and thinking of the Tsabong communities on the scope of the challenges surrounding potential collaboration between the traditional healers and the biomedical practitioners.

\section{INTRODUCTION}

The use of Indigenous Knowledge Systems (IKS) through the use of traditional healers' therapies in the care field has been found to be critical, especially in this era of HIV/AIDS. This is because of the sense of desperation that the HIV/AIDS pandemic has created and the enormous costs of medication, which most societies cannot afford to meet (ICASO, 2002; Pinky, 2001; UNAIDS, 2000). Despite the advice of the World Health Organisation (WHO) to developing countries to consider healthy collaboration between biomedical practitioners and traditional healers because of the scarcity of human resources, not much has been achieved in that direction in Botswana (UNAIDS, 2000; WHO, 1978). The advice is, however, still timely and borne out of the realisation of the magnitude of treatment and care that people - especially those living with HIV/AIDS - need, despite the scarcity of economic and human resources. This is critical as developing countries still face the unrelenting HIV/AIDS epidemic that has killed more than three million people in the world since it began. Developing countries have borne the brunt of this loss (UNAIDS/WHO, 2005). The need to fulfil the sixth Millennium Development Goal (MDG), which calls for halting and reversing the spread of HIV by 2015, makes it even more urgent and critical that effective and formidable engagement by both biomedical and the traditional healers be explored (NACA, 2008; UNAIDS, 2000).

Since 2001, when the national ARV roll out was launched in Botswana, the administration and access to ARVs and the commensurate treatment logistics continue to take a massive share of the country's national budget (Kang'ethe, 2006; NACA, 2003). With declining diamond sales as a result of declining global markets and the impact of the current global recession in Botswana, as well as the extremely slow economic diversification away from mineral dependence, it is essential to explore alternative prevention, care and treatment mechanisms to fill the ever-widening treatment gaps which the unrelenting epidemic is creating in the country. Relatively cost-effective measures and strategies, such as using the services of the traditional healers and perhaps even the community home-based care institutions that have been providing relief to the congested health services, need to be strengthened to provide reliable and muchneeded relief. This is to possibly cushion the apparent glaring economic challenge likely to constrain the requisite resources to meet treatment, care and support (Jackson, 2002; WHO, 2002).

The traditional healers in Botswana, if well trained, prepared, accepted and recognised, could fill in some of the treatment gaps created by the lack of adequately trained biomedical practitioners, as is the case in most developing countries (Kang'ethe, 2009a; UNAIDS, 2000). However, Botswana's social infrastructure gaps in terms of health facilities and health posts are not enormous in that the country is one of the success stories in the developing world and is 
renowned for having adequate health facilities. More specifically, it is estimated that $85 \%$ of the population is within a $15 \mathrm{~km}$ radius and $76 \%$ within walking distance of such facilities (Kang'ethe, 2008; Munodawafa, 1998). But that has not in any way removed the human resource gap that the country has sunk into since the start of the epidemic (NACA, 2003).

However, human resource gaps bite harder in Botswana in this era of the HIV/AIDS epidemic as the country has the highest prevalence of HIV/AIDS in the world (NACA, 2008). Many health facilities, especially in deep rural areas, are managed by nurses and family welfare educators, whose capacity to treat and administer the ARVs may be constrained. In some cases the community home-based care program nurses are forced to leave their duties attending to CHBC clients at their homes and reassigned to new duties in the clinics (Kang'ethe, 2006). The exit of nurses from Botswana, just as in other developing countries, to the Western world in pursuit of lucrative salaries has also widened the human resource gap in the country (NACA, 2005; WHO, 2002). The government has also been slow in responding to staffing challenges, since it demands that all the foreign nurses have to be registered with the Botswana Nursing Council. Apparently, the Council is not sensitive to the plight of the health situation on the ground in that it has not been flexible enough to permit foreign nurses whose training curriculum differs slightly from that in Botswana. In view of this human resource environment, collaboration of traditional healers with modern biomedical practitioners needs to be strengthened (Kang'ethe, 2006, 2009a).

But the integration of the traditional healers into the mainstream health system also raises several challenges. This is probably because the traditional healers of Africa use rituals in combination with herbal remedies, making some aspects of their therapeutic systems not acceptable or comprehensible to scientific analysis. There are well-founded fears within the medical fraternity that some practices of the healers may actually spread rather than prevent the disease. Most healers are not trained in sterilisation techniques. The effects of this can be deadly, as many of the healers use tools such as razor blades to introduce traditional medicines into the bloodstream. Such concerns have in turn led to modern science being regarded as infallible, as representing absolute truth. It is because of this faith in modern medicine that the traditional healers in Africa are now regarded as primitive witch doctors (King \& Homsy, 1997). The consequence has been widespread attempts by the medical fraternity in Botswana to discourage people from seeing traditional healers and to encourage them to go to the biomedical practitioners in an attempt to combat the AIDS crisis (Kang'ethe, 2006).

Ironically, though a number of their medical practices seem to be effective, modern science has failed to find a cure for AIDS and much remains unclear, especially in the way they handle HIV/AIDS cases. Traditional healers, on the other hand do not provide evidence of their healing procedures. There is also no proper and robust follow up of their diagnostic procedures (King \& Homsy, 1997). Members of the medical fraternity are of the opinion that, while they appreciate healers' services, the latter do not have the requisite skills to diagnose the HIV/AIDS disease. This is worrisome, because statistics show that as many as $80 \%$ of the population in some poor countries may be relying on the services of the traditional healers. There is therefore a need to look into the work of the healers and their operational challenges. This would call for an environment where their services are cross-checked by qualified biomedical practitioners. Such a strategy makes moves to promote collaboration between the two systems even more urgent (Kang'ethe, 2009a; UNAIDS, 2000; WHO, 2002). 


\section{METHODS AND STUDY SETTINGS}

\section{Research design}

The study was conducted according to a qualitative research design. It was also descriptive, explanatory and exploratory in nature. This justified the use of participatory methodologies of focus group discussions complemented with data from in-depth one-to-one interviews. Participant observations helped reveal some emotionally charged attitudes that added to the richness of the qualitative data. This qualitative research study sought to explore the opinions, perceptions, thinking, feelings, attitudes and perceptions of the support group members, the health service providers and a few leaders and administrators on the impact of the stigma of HIV/AIDS, and also to bring to the fore challenges that continue to undermine prevention efforts in Tsabong District. The researcher and his team formed the primary instrument for data collection and analysis (Neuman, 2007; Rubin \& Babbie, 2008).

\section{Research instrument}

An interview guide was used to guide 6 focus group discussions, five from the five support groups of people living with HIV/AIDS in the District, and the sixth for the service providers of the Ghakibane village, including the Tsabong District AIDS Coordinator (DAC) and his Peace Corps, and six in-depth one-to-one interviews, four with the church leaders or their representatives, and two with the Werda and Ghakibane village chiefs (dikgosis). The interview guide consisted of open-ended questions that guided the discussions. Though the instrument had been constructed to take a maximum of 90 minutes, in some settings the discussions took slightly more time.

\section{Sample selection criteria, data collection and procedure}

Convenience sampling and snowballing techniques were used to effect sample selection. This is justified because the research team targeted all the members of the support groups in the Tsabong region, the chiefs (digkosis) who were available, and all the church leaders with whom the research team could secure an appointment easily. It was the research team's wish to interview the health service providers, but the team only managed to have only one focus group discussion in Gakhibane consisting of a nurse, social worker, teacher, Peace Corps volunteer and the DAC. In total, 51 women and 17 men were involved in the study.

BONEPWA, through a letter and several telephonic communications, obtained permission from the office of the District AIDS Coordinator to contact and obtain consent from the target sample. All the focus groups and the one-to-one interviews were held at the locality of the people, or where the support groups usually met. This was in the clinics or the health centres. The nurses who were usually working with the support groups joined the focus group discussions of their support group members. They reinforced, corroborated, cross-checked, contrasted and confirmed the support group's opinions and views.

The focus group discussions were facilitated by this author plus two other officers from BONEPWA who acted as research assistants. ${ }^{1}$ While one person asked the questions, the other two wrote responses and observed and noted any behavioural responses from the participants. This enriched the data from the spoken reality. The participants' selection criteria did not consider factors such as age and gender. Notes, probing questions and discussions were strategies for collecting the data.

1 The author acknowledges the role of Zolani Kraai and Anna Lee of Forud Syd International as part of the data-gathering team. 


\section{Data analysis}

Data analysis used the content analysis method. The data-analysis process started with putting together the piles of crude field data that had been roughly jotted down. The process of harmonising and sorting the crude data was important, because some data were in Setswana, while some were in English. The data were then sorted with the use of codes. This enabled the data to be arranged easily in groups, which were divided into themes and sub-themes. This formed the basis of analysis. Quotes, words, analogies, proverbs and jotted notes were included in the data-collection process, while assessment of the researcher and his team of the participants' temperaments and gestures influenced some findings. The findings produced several themes such as the critical need for collaboration, poverty and ARV defaulting, the leadership role in the fight against HIV/AIDS, etc.

\section{Ethical and legal requirements}

The study was administratively and ethically correct in that all the communications and arrangement of the focus group discussions and interviews were channelled through the office of the Tsabong AIDS Coordinator. The office of the District Commissioner had also been informed of the exercise well in advance. The District AIDS coordinator had also written to the targeted samples for informed consent. The Tsabong DAC understood the activity as one of the BONEPWA planned activities for Skillshare and Forum Syd project activities. He was grateful because the results could inform robust policy decisions and interventions to curb the level of stigma in Tsabong, and also to possibly come out with evidence-based factors undermining the prevention efforts among the PLWHA in Tsabong.

Conducting of focus group discussions as part of the organisations working procedures did not have to follow the research procedures as spelled out by the Ministry of Health's Human Research and Development Committee board.

\section{Research domain justification}

Data for this article were obtained from empirical research conducted in October 2008 in the Tsabong District of Botswana. The BONEPWA team chose Tsabong District as their research domain because it believed that this District was lagging behind other districts in HIV/AIDS interventions. The organisation's 2004 visit to the District had given some indication that the area could be suffering from high levels of stigma and discrimination. While many researchers had studied many other districts in the country, Tsabong was avoided because of its distance from Gaborone, its aridity and the geographical terrain. This justified BONEPWA's interest in the area. While the Skillshare project had programmed to conduct the research in the area, Forum Syd was also engaged in a similar activity to assess the level of stigma in the region. The two projects of the BONEPWA organisation then joined hands to spearhead a research undertaking. 


\section{FINDINGS}

TABLE 1

PARTICIPANTS' GENDER AND SAMPLE DISTRIBUTION

\begin{tabular}{|c|l|c|c|}
\hline \multirow{2}{*}{ NO } & \multirow{2}{*}{ Support group/Service providers/Dikgosis } & \multicolumn{2}{|c|}{ Gender } \\
\cline { 3 - 4 } & & Male & Female \\
\hline 1 & Nkinola SG & 0 & 4 \\
\hline 2 & Omaweneno SG & 4 & 16 \\
\hline 3 & Draihook & 3 & 13 \\
\hline 4 & Tsabong SG & 0 & 8 \\
\hline 5 & Gakhibane SG & 3 & 2 \\
\hline 6 & Service providers & 2 & 2 \\
\hline 7 & Churches & 2 & 0 \\
\hline 8 & Chiefs (Dikgosis) & $\mathbf{1 7}$ & $\mathbf{5 1}$ \\
\hline TOTAL & & & \\
\hline
\end{tabular}

\section{Profile of the participants}

The research did not take into account the age and educational levels of the participants. It was concerned with the views, thinking and perspectives of people in the area to gather informed empirical and evidence-based data to inform the interventional direction. The gender profile indicated a preponderance of women as opposed to men. Participants consisted of 68 participants: 57 PLWHAs (10 males and 47 females); two community leaders or dikgosis; four church leaders or their representatives; five service providers (Tsabong District AIDS Coordinator (DAC), Tsabong Peace Corps Volunteer, a teacher, a nurse and a social worker). The service providers formed one focus group discussion. The research team considered their focus group important to correct, augment, confirm and cross-check the data from the other three sets (PLWHAs, dikgosis and church leaders).

From the research team's subjective perspective, the PLWHA respondents in all the focus groups discussion, but very conspicuously in Werda and Onawemeno villages, appeared to be facing acute nutritional challenges. Most PLWHAs indicated that finding sufficient food to ensure the smooth working of the ARVs was a big challenge. Most of the respondents indicated that they were poor and had a low educational background, or they had dropped out early from school and that it was difficult for them to get any formal employment other than seasonal piece jobs (temporary casual jobs). The majority of the respondents stated that they were taking excessive alcohol and sometimes behaved irresponsibly because of life's frustration and challenges. The two chiefs happened to be HIV/AIDS advocates, while one stated he was to living positively with the virus.

\section{Licensing of healers will strengthen collaboration}

The Werda chief (kgosi), supported by close to half of the research participants in the study area, emphasised that for traditional healers to be effective and stop deceiving people that they can heal AIDS, they needed to be fully registered with the Botswana Dingaka Association. The research team learned that for a healer to qualify for registration, he/she must meet some minimum set of standards such as knowledge and skills, hygiene, experience and knowledge of the use of operational tools. Since these standard packages were set in consultation with 
biomedical practitioners and government health agents, they were a form of collaboration that would ensure a better service delivery deal. The Werda kgosi had this to say:

"I tell my people to ask for the license from the healers when accessing their services."

"Some healers have killed people in my village. I have warned the residents to scrutinize and assess those who are effective. Healer's registration needs to be enforced."

"Clients' medical safety calls for healers' consultation and collaboration with biomedical practitioners and government health agents."

Close to one third of all the research respondents indicated that even if traditional healers have been able to handle some diseases successfully, some of them were unhygienic and were out to cheat people out of their money as they could not heal some of the diseases such as AIDS. Some people, especially from the support groups of Draihook, Onaweneno and Nkinola, indicated their realisation that most of the HIV-positive people accessing the services of the healers were in danger, as they are forced to go to the clinics as a last resort when they are very weak. The following sentiments were expressed by research participants on this issue:

"Many people living with the virus and accessing the services of the healers are dying fast in the area."

"We know some people who have died in the hands of the healers being cheated that the medication they get could heal AIDS."

"Why can't the healers be shown modern tricks by the modern biomedical practitioners. They can improve their service delivery."

"At least some of us now understand that combining the two sets of medication compromises one's immunity. But many do not appear to know that. They have been confused by the healers."

\section{Conflict of the two medical therapeutic systems leaves clients confused and desperate}

Close to three quarters of the research participants in the study area indicated that Tsabong area residents had a lot of confidence in the traditional healers, but were confused by the negative remarks and the disapproval they heard from the biomedical practitioners. This they said made the healers and themselves develop a negative opinion of the modern biomedical practitioners. The research team learnt that nurses from the Tsabong Hospital support group indicated that as a way to mitigate the impasse and confusion of the clients caught between the two medical systems, they often ask the clients who get medication from the healers to bring it to them so that they could advise the clients further. But the healers were also disapproving of that. Participants further indicated that the conflict between the healers and the modern biomedical practitioners led HIV/AIDS clients to mix the two systems at the risk of their immunity. Majority of the participants registered the opinion that if government could make the two groups of therapists sit together, both can tap something from each other's skill and advantages, and hence make their clients realize the benefits of collaboration.

\section{Need for control and harmonisation of the health services}

Almost all the research participants blamed the government for failing to harmonise health service provision to ensure that traditional healers work in tandem with the biomedical practitioners. They indicated that since health is a human right for all the citizenry, the quality of medication and service delivery needed to be managed and harmonised. In Werda village, 
for example, a case of a person who died while being treated by the healer was referred to, with participants pointing an accusing finger at the health authorities for not addressing the impasse. Participants therefore recommended that the government move fast to harmonise and bring together and control all the service delivery mechanisms. This, they pointed out, could guarantee and ensure confident and high-quality service delivery.

\section{Complementarity of the two service system useful, especially in areas where medical services are weak}

More than half of the research respondents indicated that since traditional healers have been in the field since time immemorial, and are still professionally engaged by many community members, while most knew varied treatment therapies, it was important that measures be put in place by the government whereby the two sets of practitioners can exchange and complement one another. The research respondents believed that the healers had a lot of knowledge and practices that biomedical practitioners can learn from. For example, healers could be better in diagnosing spiritual diseases than the biomedical practitioners. Participants strongly indicated a worry over the existing bad blood between the two systems, the results of which were detrimental to the clients' immunity and general health. They had this to say:

"These practitioners need one another. It is only the government that is not bringing them together fast."

"Some healers can deal with some diseases better than the biomedical practitioners."

"The animosity and bad blood between the two sets of practitioners only jeopardise the health of the desperate clients."

\section{DISCUSSIONS OF THE FINDINGS}

The Tsabong study conspicuously indicated the more conspicuous position of women in responding to issues as far as national campaign against HIV/AIDS was concerned. A recent study by Kang'ethe (2009b) has shown that inadequate male involvement is a characteristic that cuts across all regions in Botswana. It is recommended that the men's sector be decentralised to mobilise men to participate in issues of national importance, such as combating HIV/AIDS. Most research in the country proves that HIV/AIDS programmes in Botswana enlist the support of women more than men. For instance, Atta and Fidzani (1996) found that over $50 \%$ of most CHBC programme volunteers are women, whose economic circumstances were pathetic. The support of men in most HIV/AIDS programmes is very important. This is because men have leadership and economic powers that can help mobilise the resources better than women can. The government, donors and NGOs need to financially support the men's sector to continue the good work of mobilising men to become involved in health-related campaigns.

Poverty was reported to be a serious deterrent to achieving an optimal response to the ARV roll out in Tsabong. Findings from Kang'ethe's studies in 2004 and 2006 in Kanye indicate that HIV/AIDS is a poverty-friendly disease. This means that HIV/AIDS takes an increasingly heavy toll on the lives of the breadwinners, with the result that many families are affected by shortages of food and other necessities (Kang'ethe, 2004, 2006). The government and NGOs need to assess the poverty situation of people living with HIV/AIDS and put interventions such as helping them financially to start income-generating activities (IGAs) to address the situation, otherwise poverty could act as a deterrent to prevention efforts. Such intervention could be one of the most plausible ways to fight off poverty and the consequential nutritional challenges. 
Findings by MOH/JHPIEGO (2009) found that many people were asking for food assistance because of poverty. The government, civil society and other HIV/AIDS-friendly organisations need to come out with sustainable strategies to ensure food security among PLWHAs.

The idea of licensing all traditional healers is timely and long overdue. Just as the licensing of other medical bodies such as doctors and pharmacists is essential, so traditional healers also need to be fully licensed. This is because they are dealing with the health of human beings whose safety needs to be guaranteed (Jackson, 2002; Pinky, 2001). It is important to address this issue because much of the literature indicates that the training and licensing of healers is not institutionalised in many developing countries, Botswana included. This has made it difficult to reach and train them regularly and in a standardised manner. Quality control of healers is therefore difficult in the absence of officially recognised licensing procedures. This also implies that monitoring and evaluating their methods is difficult and renders them not credible and professionally untrustworthy. Traditional healers generally lack detailed anatomical and physiological knowledge (UNAIDS, 2000). Since health is a human right to which all are entitled, the government of Botswana should ensure, through policy regulations and procedures, that all the informal health practitioners offer effective and tested services. Licensing process would require collaboration with people of reputable medical backgrounds to assess the tools, hygiene, skills and knowledge of the practitioners (Fako, 1989; Jackson, 2002; Pinky, 2001).

The Government of Botswana has through its Ministry of Health for a long time had a policy of promoting the working cooperation between modern and traditional medicine through supporting the operations of the Botswana Dingaka AIDS Awareness Training Project. This project, for instance, ran in 1991 and 1993 with the objective of training traditional healers as trainers of trainers (TOTs), so that their training could snowball and mainstream expertise to the other healers. Unfortunately, the government has not been very serious about scrutinising the activities of the healers. This has left them unchecked to the extent that they sometimes prescribe medication and invent myths that compromise the health of the citizens (WHO, 1991; Jackson, 2002). There is widespread concern that many projects in different countries involving integration of the healers into the mainstream health programmes do not provide systematic follow-up of healers after their initial training. Such follow-up is essential to support healers in dealing with unfamiliar issues such as condom use, and coping with death and dying. This has sometimes led to frightening messages and diagnosis of people living with HIV/AIDS (King \& Homsy (1997).

Having the biomedical practitioners work from one perspective and the healers from another has left clients in a dilemma and feeling desperate. Consultation and cross-pollination of skills and knowledge between the two medical players is recommended (Pinky, 2001). Concerns over the moral and ethical approaches associated with the healers' therapies, their hygiene, their anatomical and physiological knowledge to effect diagnosis, and the fact that they want to keep information about some of their herbal concoctions secret to themselves calls for a paradigm shift in all these practices. Healers behave this way because they consider their information as derived from spiritual divination. Collaboration and interrogating their services are critical to safeguard the health rights of citizens and ensure that they are in safe hands (King \& Homsy, 1997; WHO, 1991). To this end, traditional healers, though important players in the medical field, have at times endangered the lives of their clients (BONEPWA, 2008; Kang'ethe, 2006, 2009a). Their diagnosis and tools especially need scrutiny by biomedical practitioners and government health agents. Some of their treatment tools have not been clinically clean, with 
some using tools such as one razor blade for different clients and this making viral transmission possible, while others have sometimes given their clients wrong treatment and unethical therapies. For instance, some tell their clients without any sensible scientific diagnosis that they need to sleep with virgin girls in order to cure AIDS. This is really endangering the lives of the clients and others, and also criminalises their therapeutic interventions (Kang'ethe, 2009a; WHO, 2002). In Botswana such practices compromise the attainment of Vision 2016 goals such as the one envisaging a healthy nation; they are also an obstacle to achieving universal access and the Millennium Development Goal Number 6 of halting the spread of the epidemic (UNDP, 2004; Vision 2016).

It is rumoured in some villages in Botswana that some unscrupulous healers even have sex with their clients as part of an intervention therapy. This, if it can be proved, is unethical, morally wrong and criminal, and is serious enough to warrant thorough investigation. Ironically, this has not eroded the dignity and popularity of the traditional healers one bit. In fact, the literature holds that many patients in some of the developing countries have continued to prefer to be treated by a traditional healer instead of, or in addition to, a Western-trained physician (Fako, 1989). Some healers have lined up their therapies in line with the demands of the HIV/AIDS epidemic. They are promoting the importance of practising safe sex and upholding traditional values. Those who visit the healers, especially clients with sexually transmitted diseases including HIV/AIDS, are given advice such as avoiding sex with prostitutes as well as limiting the number of sexual partners. The healers also encourage people to practise non-penetrative sex, such as thigh sex. In addition, the healers have begun promoting modern methods of AIDS prevention. Most healers now sell or give out condoms to their clients (King \& Homsy, 1997; UNAIDS, 2000).

This sends a signal to both biomedical practitioners and government agents to be realistic and consider traditional healers as important players in the battle against HIV/AIDS. This is because considerable prejudice still remains ingrained among many biomedical health practitioners about the justification, validity and integrity of traditional medical practices and practitioners. In the minds of many biomedical practitioners the traditional healers' anatomical and physiological skills are still doubtful and without valid scientific basis (Green, 1994). This, therefore, indicates a therapeutic lacuna that could be compromising the health rights of citizens. However, the WHO has recognised the importance of traditional medicine to primary health care, and of the need to include healers in national health strategies and policies (WHO, 1991). This is to optimally realise the benefits of collaboration.

Advances in the health field have necessitated heightened scrutiny and hygiene-related criticisms against informal health practitioners such as traditional healers. Since each of the two systems, that is biomedical and traditional healers, work to defend their professional turf, this has resulted in professional conflict between them, with biomedical practitioners viewing traditional healers as paraprofessionals with no proper diagnostic skills and knowledge, and therefore confusing and lowering their moral integrity as well as their medical ethics. Literature from research conducted in Kanye in 2005-2006 indicates a negatively orchestrated campaign against the healers by the members of modern medical fraternity (Kang'ethe, 2006, 2009a). On the other hand, the healers insist on their indispensability in that they have been in the field with people long before the advent of "white man's medication" and people have confidence with them (Green, 1994). They are also proud that they have been able to diagnose and treat almost many varied diseases without any paper qualifications. In fact, research indicates that some healers can deal with some diseases with greater critical success than the biomedical 
practitioners can (Green, 1994). People have also viewed their therapy as having immense social and cultural significance as opposed to modern biomedical services. In fact, healers are historically known to have adequately treated diseases of a psychiatric nature with greater ease than their biomedical colleagues (UNAIDS, 2000). The government is challenged to create a platform to map out collaboration strategies between the two systems. Each can benefit and bolster the other (Kang'ethe, 2006, 2009a; Pinky, 2001).

Lack of harmonisation and collaboration of the services of the biomedical practitioners and traditional healers has left a therapeutic lacuna that could compromise the health and safety of citizens. This gap has been exploited and widened by the practitioners from each sphere struggling to outdo one another. This has in turn led to unprofessional actions and mischief, especially from the traditional healers. It may also lead to some biomedical practitioners continuing to create a rift and bad blood between them, and to the healers dismissing, discrediting and disregarding the medical practitioners (Kang'ethe, 2006, 2009a). That notwithstanding, it is this author's view that the services of the traditional healers be subjected to scrutiny, because in most cases their medication and diagnostic tools have not been tested for validity and reliability (UNAIDS, 2000). Lack of proper control of medication that goes to the clients can lead to the use of the two medication sets in tandem. The effects of combining traditional and biomedical treatments are not known and may be harmful, because of the untested methods and treatments of the traditional healers. Use of the two systems in tandem with the clients could lead to conflict and create an unethical environment (Kang'ethe, 2006, 2009a; UNAIDS, 2000).

Harmonisation of the services from the different medical players would ensure that all the messages, tools of operations and treatment modalities are understood by members of the medical fraternity and the government in general. As the situation currently stands, the treatment, medication, diagnostic skills and proficiency of the healers are not adequately understood by the government. Wrong messages are specially causing havoc in the treatment and response process, especially to people living with the virus (Jackson, 2002). This is unacceptable, because the government is answerable for the health standards of the practitioners. Harmonisation will also ensure and strengthen the licensing process and procedures. This author recommends that the Botswana Ministry of Health move fast to control the operations and diagnostic procedures of the traditional healers. Cases of clients dying in the hands of the healers in Tsabong, with other clients going to medical practitioners only once they are very weak, call for more control of the healers and their diagnosis (BONEPWA, 2008). Collaborating between the two systems can ensure efficiency in the use of two medical systems.

The issue of collaboration is also critical, given the inadequate human and medical services in most parts of the world (UNAIDS, 2000; WHO, 2002). Even though current health thinking and advocacy hold that biomedical practitioners can today handle virtually all medical diagnoses, such doctors are fewer in number compared to the traditional healers and their services are sometimes unaffordable to poor people. But this is not always true. For instance, even in Botswana some clients prefer traditional healers to treat certain diseases such as mental illnesses. This is because they believe those illnesses are a result of supernatural forces or vengeance from unappeased ancestral spirits and, since traditional healers are known to intervene in such situations, people are open to, and able to access, help (UNAIDS, 2000). 
Also a wide variety of the literature pivotally points to the need for collaboration between the two medical systems. This is strengthened by the fact that traditional healers are the preferred and most accessible care providers in Africa. They have been trained as educators and counsellors to disseminate HIV/AIDS information and promote prevention practices among their peers and communities (King \& Homsy, 1997). Furthermore, healers are accessible, affordable, acceptable and culturally appropriate and thereby fulfil the major UNAIDS criteria for low-cost and effective health care service delivery necessary in Sub-Saharan African settings. The fact is also that traditional medicine is deeply rooted in the beliefs, values, social organisation and customary behaviour patterns of each community (Fabrega, 1974; Jackson, 2002). A close examination of the two systems and the way they can complement one another is critical. Their collaboration can bring effective service delivery to especially people living with HIV/AIDS. This is likely to make a positive advance towards meeting the country's Vision 2016 tenets of a healthy nation and the realisation of its Millennium Development Goals of halting the epidemic and improving medical access for its citizenry (UNDP, 2004; Vision 2016, 1997).

\section{CONCLUSION}

Inadequate human resources, especially of biomedical practitioners amid the unrelenting cases of HIV/AIDS in Botswana, calls for exploration of other treatment methodologies to complement the mainstream health systems. The large number of the traditional healers, as well as their cultural and social appropriateness, makes them suitable complements of the modern biomedical practitioners. Healers' collaboration with biomedical practitioners is likely to enhance their hygiene, anatomical and physiological knowledge, ethics and any moral lapses that may characterise their treatment. Healers would in return possibly be able to educate the biomedical practitioners on how to deal with especially herbal and other treatment strategies, especially of a spiritual origin. Collaboration between the two systems can possibly advance treatment modalities in Botswana significantly.

\section{REFERENCES}

ATTA, J.K. \& FIDZANI, N.H. 1996. Baseline study for Community Home Based Care Programme for Terminally ill HIV/AIDS patients in Botswana. NACP 31. AIDS STD unit, Gaborone, Botswana. Aukland.

BONEPWA .2008. An exploratory informal research survey investigating the state of stigma and discrimination in tsabong done on 27th-31st October 2008 by Bonepwa. A Draft Report.

FABREGA, H. 1974. Disease and social behaviour: an interdisciplinary perspective. Chapter 1. Cambridge, Mass: M.I.T. Press.

FAKO, T.T. 1989. Social and psychological factors associated with willingness to test for HIV. Studies of Family Planning, 20(3):147-157.

GREEN, E. 1994. AIDS and STDs in Africa: bridging the gap between traditional healers and modern medicine. Oxford: West View Press.

INTERNATIONAL COUNCIL OF AIDS SERVICE ORGANIZATION (ICASO). 2002. HIV/AIDS \& Human Rights. The International Guidelines on HIV/AIDS and Human Rights. 
JACKSON, H. 2002. AIDS AFRICA. Continent in crises. Safaids, Avondale, Harare, Zimbabwe.

KANG'ETHE, S.M 2004. Issues and challenges of community home based care in Africa. The case of Botswana. Department of Social Work, Faculty of Social Sciences. University of Botswana. (Research essay for Masters degree in Social Work)

KANG'ETHE, S.M. 2006. Contribution of caregivers in community home based care programmes: the case of Kanye, Botswana. University of North West, South Africa. (PhD thesis)

KANG'ETHE, S.M. 2009a. Traditional healers as caregivers to HIV/AID patients. Journal of Social Aspects of HIV/AIDS, 6(2):83-91.

KANG'ETHE, S.M. 2009b. Inadequate male involvement in health issues. The cause of gender skewed HIV and AIDS situations in Botswana. In: MAUNDENI, T., OSEI HWEDIE, B.Z., MUKAAMAMBO, E. \& NTSEANE, P.G. (eds) Male involvement in sexual and reproductive health. Prevention of violence and HIV/AIDS in Botswana. Made Plain Communications, Cape Town.

KING, R. \& HOMSY, J. 1997. Involving traditional healers in AIDS education and counselling in sub-Saharan Africa: a review. AIDS, 11:Suppl. A:S181-2.

MOH/JHPIEGO. 2009. Situational analysis of the care and treatment needs of PLWHA in Botswana. Draft Report. Gaborone.

MUNODAWAFA, D. 1998. Evaluation of the CHBC pilot project (Molepolole \& Tutume Sub District). NACP 41 Gaborone. February 1998.

NATIONAL AIDS COORDINATING AGENCY (NACA). 2003. Botswana 2003 Second Generation HIV/AIDS Surveillance. A Technical Report.

NATIONAL AIDS COORDINATING AGENCY (NACA). 2005. Botswana Second Generations HIV/AIDS Surveillance. Technical Report. Gaborone.

NATIONAL AIDS COORDINATING AGENCY (NACA). 2008. Progress report of the National Response to the UNGASS Declaration of commitment on HIV/AIDS. ACHAP/UNAIDS.

NEUMAN, L.W. 2007. Social research methods-quantitative and qualitative approaches. Boston, MA: Allyn \& Bacon.

PINKY, M. 2001. The role of traditional healers and doctors, coping mechanism of CHBC patients and the family. Published Abstract no. 38 on 1st Regional CHBC conference, March 2001. Boipuso Hall, Gaborone.

RUBIN, A. \& BABBIE, E.R. 2008. Research methods for social work $\left(6^{\text {th }} \mathrm{ed}\right)$. Belmont, CA: Brooks/Cole.

UNAIDS. 2000. Collaboration with traditional healers in HIV/AIDS prevention and care in Sub-Saharan Africa. A literature Review, Geneva, Switzerland.

UNAIDS. 2002. Improving access to care in developing countries. Lessons from practice, research, resources and partnerships. World health Organization. Geneva, Switzerland.

UNAIDS/WHO. 2005. AIDS epidemic update. December 2005. 
UNDP. 2004. Botswana Millennium Development Goals (MDG) Status Report. Achievements, Future Challenges and Choices. Republic of Botswana. United Nations.

VISION 2016. 1997. Towards prosperity for all. Presidential task group for a long term vision for Botswana. September. Gaborone: Government Printers.

WHO. 1978. Primary health care: report of the International Conference on Primary Health Care. Alma Ata, USSR. Geneva.

WHO. 1991. Traditional healers as community health workers: a review of projects using traditional healers as community health workers. WHO/SHS/DHS/91.6.

WHO. 2002. Community home-based care in resource - limited settings. A Framework for Action. Switzerland: Geneva.

Dr Simon M Kang'ethe is a social worker for Skill Share International and attached to the Botswana Network of People Living with HIV/AIDS (BONEPWA)in Botswana. 